07.2

\title{
Одночастотная генерация арочных квантово-каскадных лазеров при комнатной температуре
}

\author{
(C) А.В. Бабичев ${ }^{1}$, А.Г. Гладышев ${ }^{2}$, А.С. Курочкин ${ }^{1}$, В.В. Дюделев ${ }^{3}$, Е.С. Колодезный ${ }^{1}$, Г.С. Соколовский ${ }^{3,1}$, \\ В.Е. Бугров ${ }^{1}$, Л.Я. Карачинский ${ }^{1-3}$, И.И. Новиков ${ }^{1-3}$, Д.В. Денисов ${ }^{4}$, А.С. Ионов ${ }^{5}$, С.О. Слипченко ${ }^{3}$, \\ А.В. Лютецкий ${ }^{3}$, Н.А. Пихтин ${ }^{3}$, А.Ю. Егоров ${ }^{1}$
}

${ }^{1}$ Университет ИТМО, Санкт-Петербург, Россия

${ }^{2} \mathrm{OOO} \mathrm{„Коннектор} \mathrm{Оптикс“,} \mathrm{Санкт-Петербург,} \mathrm{Россия}$

${ }^{3}$ Физико-технический институт им. А.Ф. Иофффе РАН, Санкт-Петербург, Россия

${ }^{4}$ Санкт-Петербургский государственный электротехнический университет „ЛЭТИ“, Санкт-Петербург, Россия

${ }^{5}$ АО „ОКБ-Планета“, Великий Новгород, Россия

E-mail: a.babichev@mail.ioffe.ru

Поступило в Редакцию 28 января 2019 г.

В окончательной редакции 28 января 2019 г.

Принято к публикации 31 января 2019 г.

\begin{abstract}
Продемонстрирована одночастотная лазерная генерация при комнатной температуре в квантово-каскадных лазерах с арочной геометрией резонатора. Выходная оптическая мощность на длине волны вблизи $7.7 \mu \mathrm{m}$ составила более $6 \mathrm{~mW}$ в одночастотном режиме с коэффициентом подавления боковых мод до $25 \mathrm{~dB}$. Гетероструктура квантово-каскадного лазера, из которой были изготовлены арочные лазеры, реализована методом молекулярно-пучковой эпитаксии на основе гетеропары твердых растворов $\mathrm{In}_{0.53} \mathrm{Ga}_{0.47} \mathrm{As}_{\mathrm{A}} / \mathrm{Al}_{0.48} \mathrm{In}_{0.52} \mathrm{As}$, согласованных по параметру кристаллической решетки с подложкой $\operatorname{InP}$, и слоев фосфида индия, которые выполняли функцию обкладок волновода.
\end{abstract}

DOI: 10.21883/PJTF.2019.08.47618.17716

Для систем удаленного газоанализа и различных медицинских приложений требуется эффективный перестраиваемый одночастотный источник лазерного излучения в средней инфракрасной области спектра с шириной спектральной линии на полувысоте (FWHM), сравнимой c типичной шириной линии поглощения исследуемых газов при комнатной температуре (составляет около $\left.1 \mathrm{~cm}^{-1}\right)$. Одночастотные квантово-каскадные лазеры (ККЛ), впервые представленные в [1], обеспечивают лазерную генерацию со значением FWHM на уровне $1 \mathrm{~cm}^{-1}$. Основные подходы по созданию одночастотных ККЛ базируются на формировании распределенной обратной связи в геометрии внешнего резонатора [2] и в геометрии решетки, интегрированной в лазерный волновод [3]. Использование конструкции внешнего резонатора приводит к большим геометрическим размерам, чувствительности системы к механическим воздействиям, требует высокой точности позиционирования компонентов. Формирование решетки на кристалле ККЛ, обеспечивающей распределенную обратную связь, требует применения высокоточной литографии (электронно-лучевой или голографической).

Альтернативные подходы к формированию одночастотных ККЛ основаны на применении фотонных кристаллов [4], кольцевых резонаторов [3], связанных резонаторов [5], асимметричных интерферометров Маха-Цендера [6]. Результаты по формированию лазерных резонаторов сложной формы, в том числе арочных квантово-каскадных лазеров, состоящих из линейных и полукольцевых участков, представлены в работах [7-9].
Наличие полукольцевой части обеспечивает дополнительную селекцию мод и, как следствие, позволяет реализовать одночастотный режим лазерной генерации [8]. Относительная простота реализации арочных ККЛ является ключевым фактором, способным повысить выход годных изделий и снизить себестоимость их изготовления. Однако до начала проведения наших исследовательских работ достичь одночастотной лазерной генерации при комнатной температуре ККЛ подобного типа не удавалось. Максимальная температура генерации, о которой ранее сообщалось, не превышала $240 \mathrm{~K}$ [8]. В настоящей работе продемонстрирована одночастотная лазерная генерация арочных квантовокаскадных лазеров при комнатной температуре.

Гетероструктура ККЛ была выращена в компании „Коннектор Оптикс“ на промышленной установке молекулярно-пучковой эпитаксии Riber 49, оснащенной твердотельным источником мышьяка, фосфора крекерного типа и источниками марки ABI 1000 для создания потоков галлия и индия $[10,11]$. В качестве подложки использовались пластины InP c ориентацией (001), легированные серой до уровня $n=1 \cdot 10^{17} \mathrm{~cm}^{-3}$. В качестве буферного выполаживающего слоя был использован $\operatorname{In}_{0.53} \mathrm{Ga}_{0.47} \mathrm{As}$ (толщина составляет $500 \mathrm{~nm}, n=5 \cdot 10^{16} \mathrm{~cm}^{-3}$ ). Активная область включала 50 каскадов на основе гетеропары $\mathrm{In}_{0.53} \mathrm{Ga}_{0.47} \mathrm{As} / \mathrm{In}_{0.52} \mathrm{Al}_{0.48} \mathrm{As}$. Использована конструкция с двухфононным резонансным рассеянием носителей заряда [12,13]. Толщина верхней обкладки волновода (слоя InP) составила $4 \mu \mathrm{m}\left(n=1 \cdot 10^{17} \mathrm{~cm}^{-3}\right)$. В ка- 


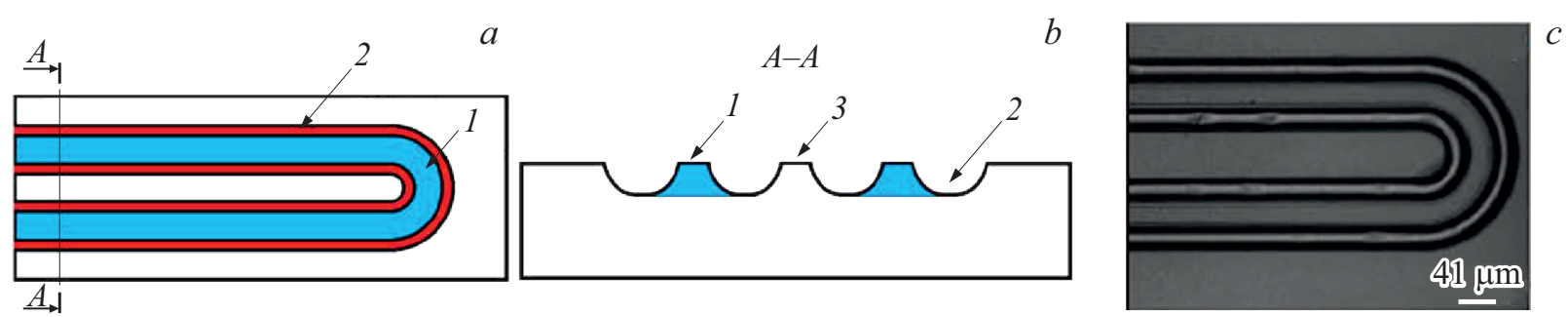

Рис. 1. Изображения, демонстрирующие вид кристалла в геометрии резонатора арочного типа. $a-$ вид сверху (схематически), $b$ - поперечное сечение (схематически), $c$ - вид сверху (изображение получено с помощью оптического микроскопа). Пояснение в тексте.
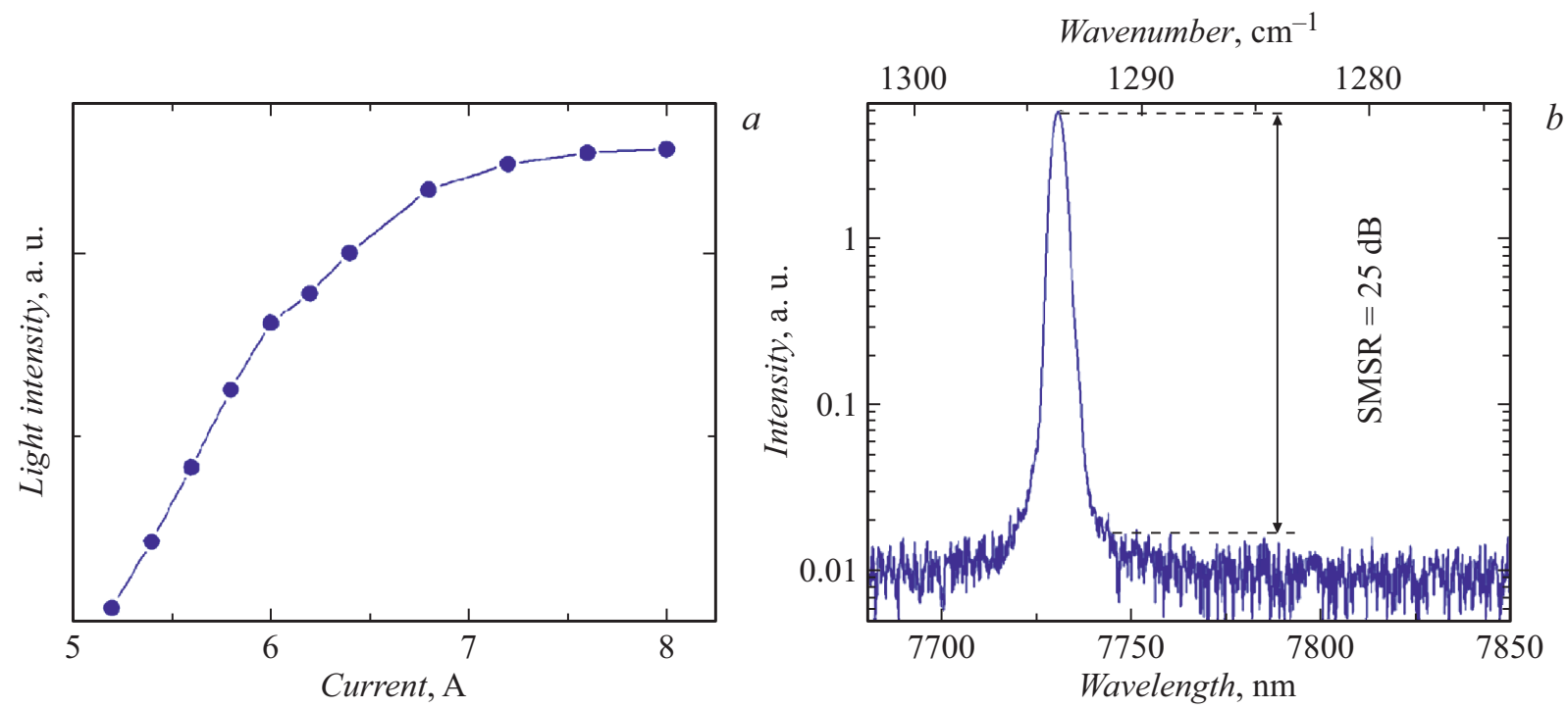

Рис. 2. $a$ - типичная ватт-амперная характеристика ККЛ в арочной геометрии резонатора, $b-$ типичный спектр лазерной генерации ККЛ с арочной геометрией резонатора (полулогарифмический масштаб, ток накачки $I=6.2 \mathrm{~A}$ ).

честве контактных слоев применялись $\operatorname{In}_{0.53} \mathrm{Ga}_{0.47} \mathrm{As}$ толщиной 100 и $20 \mathrm{~nm}$ с уровнями легирования $1 \cdot 10^{17}$ и $1 \cdot 10^{19} \mathrm{~cm}^{-3}$ соответственно. Определение структурного качества гетероструктуры, а также соответствие толщин слоев в каскадах заданным значениям осуществлялось методом рентгеновской дифрактометрии [14].

Схематическое изображение кристалла ККЛ с резонатором арочного типа представлено на рис. 1 ( $a-$ вид сверху, $b$ - поперечное сечение). Для создания арочного резонатора был использован метод формирования мезы с двойной канавкой (double-trench geometry [15]). Цифра 1 соответствует областям арочного резонатора, в которых осуществлялась токовая накачка, 2 - вытравленным областям. На рис. $1, b$ центральная пассивная меза, обозначенная цифрой 3 , покрыта диэлектриком. Формирование кристалла ККЛ проводилось по методике, аналогичной описанной ранее $[14,16]$. Ширина резонатора вблизи поверхности гетероструктуры составила $16 \mu \mathrm{m}$, длина линейных участков лазерного резонатора $1 \mathrm{~mm}$, диаметр полукольцевого участка резонатора $75 \mu \mathrm{m}$. На рис. 1, $c$ представлено типичное изображение (вид сверху) кристалла ККЛ перед монтажом на теплоотвод. Зеркала лазеров формировались скалыванием.
Отражающее и антиотражающее покрытия на сколотые грани лазера не наносились. Монтаж кристалла производился эпитаксиальной поверхностью вниз на медный теплоотвод при помощи индиевого припоя.

Ватт-амперные характеристики измерялись при пропускании импульсов тока с длительностью $70 \mathrm{~ns}$ и частотой повторения $48 \mathrm{kHz}$. Спектры лазерной генерации измерялись при помощи монохроматора МДР-23 с дифракционной решеткой $75 \mathrm{~mm}^{-1}$. Излучение регистрировалось охлаждаемым фотоприемником Vigo PVI4TE-10.6 с использованием техники синхронного детектирования [17]. Максимальная выходная оптическая мощность измерялась с помощью откалиброванного термоэлектрического преобразователя (Thorlabs S401). Bce измерения были проведены при температуре $15^{\circ} \mathrm{C}$.

Типичный вид ватт-амперной характеристики представлен на рис. 2, a. Диапазон пороговых токов лазерной генерации $\left(I_{t h}\right)$ составлял от 4.0 до $8.0 \mathrm{~A}$ для различных длин резонаторов, что соответствует оценочным значениям плотностей порогового тока $12.5-25 \mathrm{kA} / \mathrm{cm}^{2}$. Спектральные измерения показали одночастотную генерацию арочных ККЛ при комнатной температуре с величиной подавления боковых мод более $20 \mathrm{~dB}$. В част- 
ности, представленный на рис. $2, b$ типичный спектр демонстрирует одночастотную лазерную генерацию на длине волны излучения $7.7 \mu \mathrm{m}$ с коэффициентом подавления боковых мод (SMSR) $25 \mathrm{~dB}$. FWHM составляет около $4 \mathrm{~nm}\left(0.7 \mathrm{~cm}^{-1}\right)$. Пиковая мощность в режиме одночастотной генерации для различных образцов составляла 3-6.6 $\mathrm{mW}$.

Таким образом, в ходе выполнения работы изучено формирование и проведено исследование одночастотных ККЛ спектрального диапазона 7-8 $\mu \mathrm{m}$ с арочной геометрией резонатора. Продемонстрирована одночастотная лазерная генерация арочных квантово-каскадных лазеров при комнатной температуре. Максимально достигнутый коэффициент подавления боковых мод составил $25 \mathrm{~dB}$, при этом пиковая выходная оптическая мощность превысила $6 \mathrm{~mW}$. Полуширина спектра лазерной генерации не превышала $1 \mathrm{~cm}^{-1}$, что свидетельствует о возможности изготовления перестраиваемых источников лазерного излучения среднего инфракрасного диапазона на основе линейки одночастотных арочных ККЛ для спектроскопических приложений.

Работа А.В. Бабичева, А.Г. Гладышева, Е.С. Колодезного, В.Е. Бугрова, Л.Я. Карачинского, И.И. Новикова, Г.С. Соколовского, А.Ю. Егорова поддержана Министерством науки и высшего образования РФ в рамках Федеральной целевой программы „Исследования и разработки по приоритетным направлениям развития научнотехнологического комплекса России на 2014-2020 гг.“, шифр 2016-14-579-0009, соглашение № 14.578.21.0204, уникальный идентификатор RFMEFI57816X0204.

\section{Список литературы}

[1] Faist J., Gmachl C., Capasso F., Sirtori C., Sivco D.L., Baillargeon J.N., Cho A.Y. // Appl. Phys. Lett. 1997. V. 70. P. 2670-2672.

[2] Kruczek T., Fedorova K.A., Sokolovskii G.S., Teissier R., Baranov A.N., Rafailov E.U. // Appl. Phys. Lett. 2013. V. 102. P. 011124

[3] Wu D.H., Razeghi M. // APL Mater. 2017. V. 5. P. 035505.

[4] Semmel J., Nähle L., Höfling S., Forchel A. // Appl. Phys. Lett. 2007. V. 91. P. 071104.

[5] Wakayama Y., Iwamoto S., Arakawa Y. // Appl. Phys. Lett. 2010. V. 96. P. 171104.

[6] Liu P.Q., Wang X., Gmachl C.F. // Appl. Phys. Lett. 2012. V. 101. P. 161115.

[7] Liu P.Q., Sladek K., Wang X., Fan J.-Y., Gmachl C.F. // Appl. Phys. Lett. 2011. V. 99. P. 241112.

[8] Liu P.Q., Wang X., Fan J.-Y., Gmachl C.F. // Appl. Phys. Lett. 2011. V. 98. P. 061110.

[9] Zheng M.C., Zhang Y.M., Liu P.Q., Wang X., Fan J.-Y., Troccoli M., Gmachl C.F. // Opt. Eng. 2017. V. 57. P. 011001.

[10] Бабичев А.В., Гусев Г.А., Собронов А.Н., Фирсов Д.А., Воробьев Л.Е., Усикова А.А., Задиранов Ю.М., Ильинская Н.Д., Неведомский В.Н., Дюделев В.В., Соколовский Г.С., Гладышев А.Г., Карачинский Л.Я., Новиков И.И., Егоров А.Ю. // ЖТФ. 2018. Т. 88. В. 10. С. 1559-1563.

[11] Бабичев А.В., Курочкин А.С., Колодезный Е.С., Филимонов А.В., Усикова А.А., Неведомский В.Н., Гладымев А.Г.,
Карачинский Л.Я., Новиков И.И., Егоров А.Ю. // ФТП. 2018. Т. 52. В. 6. С. 597-602.

[12] Бабичев А.В., Гладымев А.Г., Курочкин А.С., Колодезный Е.С., Соколовский Г.С., Бугров В.Е., Карачинский Л.Я., Новиков И.И., Bousseksou А., Егоров А.Ю. // ФТП. 2018. Т. 52. В. 8. С. 954-757.

[13] Бабичев А.В., Гладышев А.Г., Филимонов А.В., Неведомский В.Н., Курочкин А.С., Колодезный Е.С., Соколовский Г.С., Бугров В.Е., Карачинский Л.Я., Новиков И.И., Bousseksou A., Егоров А.Ю. // Письма в ЖТФ. 2017. Т. 43. B. 14. C. $64-71$.

[14] Бабичев А.В., Гладымев А.Г., Денисов Д.В., Карачинский Л.Я., Новиков И.И., Boulley L., Bousseksou A., Пихтин Н.А., Егоров А.Ю. // ЖТФ. 2019. В печати.

[15] Szerling A., Slivken S., Razeghi M. // Opto-Electron. Rev. 2017. V. 25. P. 205-208.

[16] Бабичев А.В., Bousseksou А., Пихтин Н.А., Тарасов И.С., Никитина Е.В., Софронов А.Н., Фирсов Д.А., Воробьев Л.Е., Новиков И.И., Карачинский Л.Я., Егоров А.Ю. // ФТП. 2016. Т. 50. В. 10. С. 1320-1324.

[17] Дюделев В.В., Лосев С.Н., Мыльников В.Ю., Бабичев А.В., Когновицкая Е.A., Слипченко С.О., Лютецкий А.В., Пихтин Н.А., Гладышев А.Г., Карачинский Л.Я., Новиков И.И., Егоров А.Ю., Кучинский В.И., Соколовский Г.С. // Оптика и спектроскопия. 2018. Т. 125. В. 3. C. 387-390. 